University of Nebraska - Lincoln

DigitalCommons@University of Nebraska - Lincoln

Faculty Papers and Publications in Animal

Science

Animal Science Department

1984

\title{
Relationship of Lactation Energy Intake and Occurence of Postweaning Estrus to Body and Back Fat Composition in Sows
}

D. E. Reese

University of Kentucky, dreese1@unl.edu

E. R. Peo, Jr.

University of Nebraska-Lincoln

A. J. Lewis

University of Nebraska-Lincoln, alewis2@unl.edu

Follow this and additional works at: https://digitalcommons.unl.edu/animalscifacpub

Part of the Animal Sciences Commons

Reese, D. E.; Peo, Jr., E. R.; and Lewis, A. J., "Relationship of Lactation Energy Intake and Occurence of Postweaning Estrus to Body and Back Fat Composition in Sows" (1984). Faculty Papers and Publications in Animal Science. 669.

https://digitalcommons.unl.edu/animalscifacpub/669

This Article is brought to you for free and open access by the Animal Science Department at DigitalCommons@University of Nebraska - Lincoln. It has been accepted for inclusion in Faculty Papers and Publications in Animal Science by an authorized administrator of DigitalCommons@University of Nebraska - Lincoln. 


\title{
RELATIONSHIP OF LACTATION ENERGY INTAKE AND OCCURRENCE OF POSTWEANING ESTRUS TO BODY AND BACKFAT COMPOSITION IN SOWS ${ }^{1}$
}

\author{
D. E. Reese ${ }^{2}$, E. R. Peo, Jr. ${ }^{3}$ and A. J. Lewis \\ University of Nebraska, \\ Lincoln $68583^{4}$
}

\section{Summary}

Forty-five crossbred primiparous sows were used to determine the relationship of lactation energy intake and the occurrence of postweaning estrus to (1) body fat (percentage), (2) lean body mass (LBM) and (3) qualitative and quantitative characteristics of adipose tissue. Sows received 8 (Lo) or $16(\mathrm{Hi}) \mathrm{Mcal}$ of metabolizable energy $(\mathrm{ME}) / \mathrm{d}$ during lactation and 5.4 $\mathrm{Mcal}$ of $\mathrm{ME} / \mathrm{d}$ postweaning. Serum samples were obtained $1 \mathrm{~d}$ before weaning ( $\mathrm{d} 0$ ) and analyzed for creatinine and urea- $\mathrm{N}$ (indices of muscle and amino acid catabolism, respectively). Subcutaneous adipose tissue samples were obtained and analyzed for total lipid and myristic, palmitic, palmitoleic, stearic, oleic and linoleic acids. Last rib backfat thickness determined at weaning was used to estimate body fat (percentage). Lean body mass was estimated from 48-h creatinine excretion rates determined on $\mathrm{d} 15$ and 16 postweaning. Sows fed the Lo diet that returned (Lo-R) and did not return (Lo-NR) to estrus by $\mathrm{d} 14$ postweaning lost more $(\mathrm{P}<.01)$ weight during lactation, gained more $(\mathrm{P}<.01)$ weight postweaning, had higher $(\mathrm{P}<.07)$ body fat (percentage) and a slight trend toward lower creatinine excretion rate than sows fed the $\mathrm{Hi}$ diet that returned to estrus (Hi-R). Adipose tissue from sows in the Lo- $R$ and Lo-NR groups had less $(P<.05)$ lipid than that from sows in the Hi-R group. Concen-

\footnotetext{
${ }^{1}$ Published as Paper No. 7190, Journal Ser. Nebraska Agr. Exp. Sta.

${ }^{2}$ Present address: Agr. Sci. Building - South, Univ. of Kentucky, Lexington.

${ }^{3}$ To whom reprint requests should be addressed.

${ }^{4}$ Dept. of Anim. Sci. Acknowledgement is made to Drs. H. J. Mersmann and R. A. Britton for technical assistance and to Blaine Hansen for assistance with data collection.

Received June 8, 1983.

Accepted November 18, 1983.
}

trations of oleic and stearic acids were lower and higher $(\mathrm{P}<.01)$, respectively, in adipose tissue from sows in the Lo-R and Lo-NR vs Hi-R groups. Sows in the Lo-R group had similar $(\mathrm{P}>.10)$ lactation weight loss, weight gain postweaning, serum urea- $\mathrm{N}$ and creatinine concentrations, creatinine excretion rate and adipose tissue characteristics, but more $(\mathrm{P}<.01)$ body fat (percentage) at weaning than sows in the Lo-NR group. The data indicate that catabolism of body fat was more deleterious to a rapid return to estrus than was catabolism of muscle tissue and that the lack of estrous activity by $\mathrm{d} 14$ postweaning cannot be explained by changes in adipose tissue composition.

(Key Words: Sows, Energy, Body Composition, Postweaning Estrus.)

\section{Introduction}

A rapid and consistent rate of estrous expression after weaning is important for efficient and profitable swine production. Numerous factors that affect the interval from weaning to first estrus in sows have been described previously (Reese et al., 1982a). Sows that lose large quantities of weight and backfat during lactation have a higher incidence of delayed estrous expression and anestrus through $70 \mathrm{~d}$ after weaning than those that experience minimal losses (Reese et al., 1982a,b).

Weight losses in lactating sows result from the catabolism of subcutaneous adipose tissue (O'Grady et al., 1975; Duee and Desmoulin, 1982). Evidence was provided by Reese et al. (1982a) that a higher rate of amino acid catabolism occurred in sows fed low vs high energy diets during lactation. It was not possible in the study to determine whether dietary amino acids or those previously incorporated into body proteins were being catabolized to the greater extent. Because loss of muscle tissue occurs in 
lactating sows (O'Grady et al., 1975; Duee and Desmoulin 1982), a possible relationship exists between muscle tissue loss and delayed estrus after weaning in energy-restricted sows. Additionally, no information is available that describes qualitative and quantitative characteristics of body fat at weaning in relation to postweaning estrus in sows.

Therefore, the experiment reported herein was designed to determine the relationship of lactation energy intake and the occurrence of postweaning estrus in primiparous sows to (1) body fat (percentage), (2) lean body mass and (3) certain qualitative and quantitative characteristics of subcutaneous adipose tissue.

\section{Experimental Procedure}

Forty-five crossbred primiparous sows were assigned randomly after parturition to either a low (Lo) or high (Hi) energy diet. Every third sow that farrowed was assigned to the $\mathrm{Hi}$ diet. The diets used in this experiment have been described previously (Reese et al., 1982a). The diets were formulated to provide average energy intakes of $8(\mathrm{Lo})$ or $16(\mathrm{Hi}) \mathrm{Mcal}$ of metaboliazble energy $(M E) \cdot$ sow $^{-1} \cdot \mathrm{d}^{-1}$ during a 28 -d lactation period. All sows received the same daily quantities of crude protein, amino acids, vitamins and minerals, which met or exceeded the recommendations of the NRC (1979). The diets were selected to produce greatly different weight and backfat losses during lactation.

Sows were moved into farrowing crates on $d$ 106 of gestation and fed $2.3 \mathrm{~kg}$ of the Hi diet daily until parturition. On d 110 of gestation, indwelling Bardex Foley $^{5}$ catheters (size 22, 5-cc balloon type) were inserted into the bladder and urine was collected for a total of $48 \mathrm{~h}$ in plastic receptacles that contained $50 \mathrm{ml}$ of a $10 \%(\mathrm{v} / \mathrm{v})$ solution of technical grade $\mathrm{HCl}$. After each 24-h period, urine was diluted with distilled water to the nearest .5 liter, thoroughly mixed and subsampled $(50 \mathrm{ml})$. The subsample was placed in a plastic cup, sealed and immediately frozen $(-20 \mathrm{C})$ until analysis for creatinine and urea- $\mathrm{N}$ as described by Frankel et al. (1970).

\footnotetext{
${ }^{5}$ C. R. Bard, Inc., Murray, NJ 07974.

${ }^{6}$ IthaCo Ultrasonic Scanoprobe, Ithaca, NY

'Vacutainer tube, Becton-Dickinson, Rutherford, NJ.

${ }^{8}$ Lidocaine hydrochloride, Med-Tech, Inc., Elwood, KS 66024 .
}

After parturition, sows were weighed and backfat measurements were obtained by ultrasonic determination ${ }^{6}$. Measurements were taken at the first and last rib and last lumbar vertebra and averaged. To minimize variation in litter size, pigs were transferred among sows irrespective of diet until d 3 after parturition. Pigs did not receive creep feed and their access to sow feed was minimal. One day before weaning, a blood sample was collected from the brachial region of each sow $3.5 \mathrm{~h}$ after the morning feeding, which consisted of one-half of the daily feed allowance. The duration of the sampling period for the entire group did not exceed $30 \mathrm{~min}$. The sample was collected in an evacuated glass tube ${ }^{7}$, placed on ice, centrifuged and aliquots of serum were transferred to sterile plastic tubes and frozen $(-20 \mathrm{C})$ until analysis for creatinine and urea- $\mathrm{N}$ by the same procedures described for urine.

After weaning, sows were weighed and backfat thickness was determined as described previously. Last rib backfat thickness was used to estimate body fat percentage $\left(r^{2}=.72\right)$ according to the equation of Whittemore et al. (1980). Pig weaning weight and the number of pigs weaned were recorded. Adipose tissue samples were obtained using a biopsy gun with an extended bore (Schied et al., 1970) from the neck area $5 \mathrm{~cm}$ lateral to the dorsal midline. For biopsy, the hair was clipped and the skin was disinfected with surgical soap and treated topically with a $2 \%$ solution of local anesthetic $^{8}$. Tissue samples were immediately placed in plastic packs, sealed after physically excluding air, and placed on dry ice until being transferred to storage $(-30 \mathrm{C})$. After sampling, wounds were treated with sulfa-urea powder.

Adipose tissue samples were analyzed for total lipid content and subsequently for individual fatty acids. Total lipid content was determined in duplicate, using the extraction procedure of Folch et al. (1957). Before analysis, the outer layer of backfat was separated from the inner layer at the visible connective tissue septum. The skin was also separated from the outer layer and discarded. Approximately $2 \mathrm{~g}$ of the outer layer was obtained for analysis. During the extraction process, the samples were blanketed with $\mathbf{N}$ and(or) solvent vapor to prevent fatty acid oxidation.

The fatty acids determined were myristic (14:0), palmitic $(16: 0)$, palmitoleic (16:1), stearic (18:0), oleic (18:1) and linoleic (18:2). Individual fatty acids were separated by gas- 
TABLE 1. EFFECT OF LACTATION ENERGY INTAKE ON THE PERCENTAGE OF SOWS IN ESTRUS BY D 14 POSTWEANING

\begin{tabular}{lcc}
\hline Item & Diet & Lo \\
\cline { 2 - 3 } No. of sows & $\mathrm{Hi}$ & 31 \\
Percentage in estrus at $14 \mathrm{~d}^{\mathrm{a}}$ & 14 & 41.9 \\
No. bledb & 92.9 & 18 \\
No. having luteal activity without & 1 & 0 \\
a detected estrusc & 1 & 0 \\
\hline
\end{tabular}

\footnotetext{
$a_{\text {Hi vs Lo }(P<.01)}$

${ }^{\mathrm{b}}$ Sows bled for progesterone analysis if estrus had not been detected by $14 \mathrm{~d}$ postweaning.

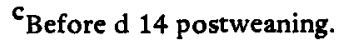

liquid chromatography with an auto-injection chromatograph ${ }^{9}$ and quantified by use of a reference standard ${ }^{10}$. Saponification and reesterification were performed in one operation according to procedures described by Supelco, Inc. ${ }^{10}$ with methanolic- $\mathrm{HCl}^{10}$ used as the methylating agent. Ethyl esters were partitioned on a column packed with SP-2330 ${ }^{10}$ after overnight conditioning at $225 \mathrm{C}$. Separation was accomplished by temperature programming with an initial column temperature of $165 \mathrm{C}$ for $1 \mathrm{~min}$. The temperature was set at $3.5 \mathrm{C} / \mathrm{min}$ up to a final temperature of $210 \mathrm{C}$. Temperature of the injection port was $235 \mathrm{C}$, and the flame ionization detector temperature was maintained at $250 \mathrm{C}$. Nitrogen flow rate was $19.7 \mathrm{ml} / \mathrm{min}$.

The weaned sows were moved into crates located in an enclosed gestation facility and fed $1.8 \mathrm{~kg} \cdot \mathrm{sow}^{-1} \cdot \mathrm{d}^{-1}$ of a gestation diet ${ }^{11}$ (Reese et al., 1982a). Sows were moved to pens containing a boar to check for estrus on a daily basis. On d 14 postweaning, sows were weighed and moved into farrowing crates to facilitate urine collection for creatinine and urea- $\mathrm{N}$ analysis as described previously. The 48-h collection period was initiated on $d 15$. Sows that were not previously detected in estrus were bled from the brachial region on $d 14$ postweaning. Sows that did not show estrus during the following $7 \mathrm{~d}$ were bled again at $\mathrm{d} 21$ postweaning. Serum samples were processed

\footnotetext{
${ }^{9}$ Model 5840, Hewlett-Packard, Avondale, PA.

${ }^{10}$ Supelco Inc., Bellefonte, PA.

$111.8 \mathrm{~kg}$ provided $5.4 \mathrm{Mcal}$ of $\mathrm{ME}$ and $254 \mathrm{~g}$ crude protein.
}

and stored as described above until analyzed for progesterone according to procedures described by Anthony et al. (1981).

Diet effects on the cumulative percentage of sows in estrus by $\mathrm{d} 14$ postweaning were tested using a linear model approach appropriate for categorical data (Grizzle et al., 1969). Day of weaning was designated as $\mathrm{d} 0$ in calculating the number of days to first estrus. Effects on the remaining response criteria were tested using least-squares analysis of variance (SAS, 1979; Steel and Torrie, 1980). Mean comparisons were made between sows fed Lo that returned (Lo-R) or did not return (Lo-NR) to estrus by d 14 postweaning and sows fed $\mathrm{Hi}$ that returned to estrus by $\mathrm{d} 14$ (Hi-R). Sows in groups Lo-R and Lo-NR were also compared. Prepartum urinary creatinine excretion rates were used as covariates to adjust the respective values obtained after weaning for initial differences. Litter size at $\mathrm{d} 3$ postpartum was used to adjust sow weight and backfat changes during lactation in addition to pig weight and litter size at weaning. Also, postpartum sow weight and backfat quantities were used to adjust changes that occurred therein during lactation.

\section{Results and Discussion}

Fewer $(\mathrm{P}<.01)$ sows fed Lo expressed estrus by $14 \mathrm{~d}$ postweaning than those fed Hi (table 1). Previous studies (Reese et al., 1982a,b) have demonstrated similar results. One sow fed the Hi diet was not detected in estrus by $d 14$ postweaning. According to serum progesterone concentrations, ovulation had occurred in the absence of a detected behavioral estrus in this sow. Sows having progesterone concentrations 
of less than $5 \mathrm{ng} / \mathrm{ml}$ were assumed to have had luteal tissue activity indicating that ovulation had occurred. Low $(<5 \mathrm{ng} / \mathrm{ml})$ progesterone concentrations were observed in all sows fed Lo that had not been detected in estrus by $d 14$ postweaning. The data confirmed that reproductive dysfunction occurred through $14 \mathrm{~d}$ postweaning in energy-restricted sows.

The relationships of energy intake and occurrence of postweaning estrus to sow and litter performance are shown in table 2 . No differences $(P>.10)$ in average litter size or pig weaning weight were observed at 2 or $4 \mathrm{wk}$ between sows in the Lo-R and Lo-NR vs Hi-R groups. Similarly, no differences were observed for the same traits between sows in the Lo-R and Lo-NR groups, although there was a tendency for the sows in the Lo-NR group to wean more pigs. Energy intake during lactation did not affect average litter size at weaning and pig weaning weight in studies where pigs received creep feed (Elsley et al., 1968, O'Grady et al., 1973; Adam and Shearer, 1975). In studies were pigs received no creep feed, energy consumption by the sow during lactation had no effect on litter size at weaning, but the response observed in pig weaning weight was variable (Reese et al., 1982a,b). In view of the data reported herein, catabolism of body tissues must have occurred in sows fed the Lo diet to compensate for their energy deprivation.

Evidence of body tissue catabolism was demonstrated by the weight and backfat changes observed during lactation (table 2). Sows in the Lo-R and Lo-NR groups lost more $(\mathrm{P}<.01)$ weight during both the first and second

TABLE 2. RELATIONSHIP OF LACTATION ENERGY INTAKE AND OCCURRENCE OF POSTWEANING ESTRUS TO SOW AND LITTER PERFORMANCEa

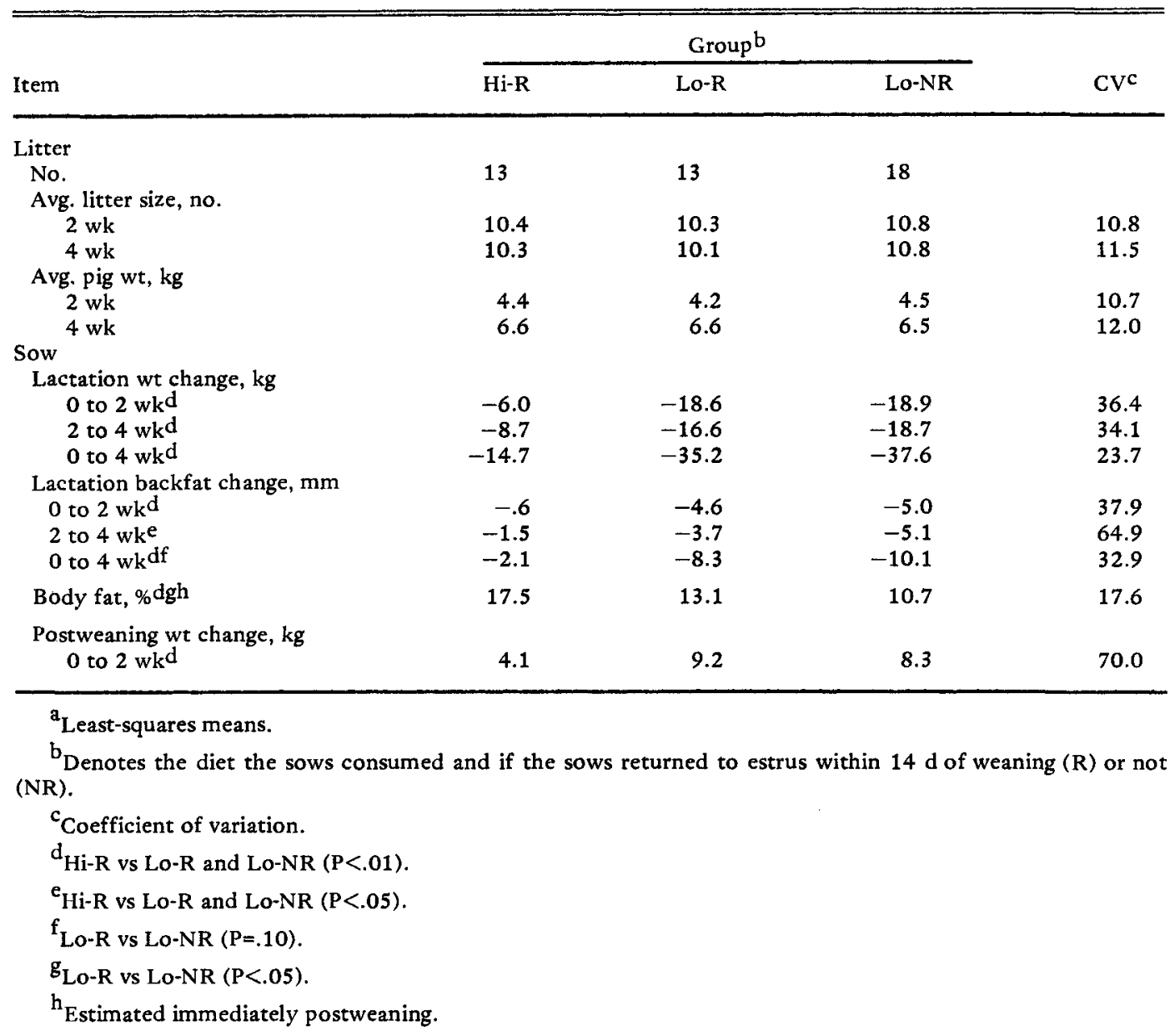


$2 \mathrm{wk}$ and therefore during the entire lactation period than those in the Hi-R group. Similar results due to energy restriction during lactation have been reported previously (Elsley et al., 1968; Adam and Shearer, 1975; O'Grady et al., 1975; Reese et al., 1982a,b). The weight loss of sows in the Lo-R group did not differ $(\mathrm{P}>$.10) from that observed for those in the Lo-NR group during any time of the lactation period. These data suggest that little relationship exists between sow weight loss during lactation and the interval between weaning and first estrus. The results of Brooks et al. (1975), Varley and Cole (1978) and Cox et al. (1983) support this conclusion. In contrast, Petherick et al. (1977) reported an association between lactation weight loss and estrous activity during lactation.

Backfat loss for sows in the Lo-R and Lo-NR groups was greater $(P<.05)$ during the first 2 $\mathrm{wk}$, the second $2 \mathrm{wk}$ and for the total lactation period than that for those in the Hi-R group. However, more striking was the fact that loss of backfat for the entire lactation period was greater $(P=.10)$ for sows in the Lo-NR group than those in the Lo- $R$ group. As expected, large differences in body fat (percentage) at weaning were observed. Sows in the Lo-R and Lo-NR groups had less $(\mathrm{P}<.01)$ body fat at weaning than those in the Hi-R group. A further reduction $(P<.05)$ in body fat content was observed in sows that experienced delayed estrus after weaning $(13.1$ vs $10.7 \%$ for the Lo-R and Lo-NR groups, respectively). Energy intake during lactation had similar effects on backfat quantities in other studies (O'Grady et al., 1975; Reese et al., 1982a,b). An explanation for the increased body fat loss by sows in the Lo-NR group compared with the Lo-R group is not easy. Because sows in the Lo-NR group weaned numerically more pigs/litter than sows in the Lo-R group, a greater reliance on body reserves to meet the needs of lactation may have elicited a greater loss of body fat. Fahmy et al. (1979) analyzed records on 738 primiparous sows and observed an increase of about $.62 \mathrm{~d}$ in the length of the interval from weaning to estrus for each pig being nursed.

Differences in body fat (percentage) at weaning between the sows in the Lo- $R$ and Lo-NR groups occurred in the absence of differences in body weight loss during lactation. This observation suggests that sow backfat thickness and body weight are poorly correlated. Whittemore et al. (1980) reported a similar observation.

The data reported herein indicate that even under situations of substantial body weight and fat losses during lactation, sows exhibited estrus by d 14 after weaning. However, when body fat losses became severe, the occurrence of postweaning estrus was affected (group Lo- $R$ vs Lo-NR). Cox et al. (1982) noted a similar situation in second parity sows.

Sow weight change from weaning to $\mathrm{d} 14$ postweaning was affected by energy intake during lactation. The weight gain of sows in the Hi-R group was less $(\mathrm{P}<.01)$ than that for sows in the Lo-R and Lo-NR groups; however, the difference in weight gain of sows in the Lo-R and Lo-NR groups was indistinguishable $(P>.10)$. Thus, weight gain after weaning appeared to be unrelated to the time at which postweaning estrus occurred. The results of Varley and Cole (1978) support this conclusion. Restriction of feed (Varley and Cole, 1976), protein (MacPherson et al., 1969; O'Grady, 1971) and energy intake (Reese et al., 1982b) during lactation also resulted in increased net sow weight gain during the subsequent gestation period.

Reasons for the compensation in weight gain exhibited by sows fed the Lo diet are not clear. Sows fed the Lo diet weighed less at weaning than sows fed $\mathrm{Hi}$, thus their energy requirements for maintenance would be lower and, consequently, more energy would be available for productive purposes. The possibility of improved nutrient utilization was refuted by Hovell et al. (1977). In that study, sows receiving low quantities of energy and protein during gestation and lactation digested dry matter, energy and $\mathrm{N}$ similar to control sows when they became anestrous. Another possibility is that a portion of the weight gain of sows fed Lo comprised abnormally large quantities of water. According to Patrick et al. (1978), feeding a high energy diet to severely malnourished children for $14 \mathrm{~d}$ resulted in a significant increase in total body water (percentage body weight). Although the sows fed Lo did not receive more ME after weaning than during lactation, an increased quantity of $\mathrm{ME}$ would become available to the sows upon weaning because the nutrient demands of lactation were removed.

The rate of amino acid catabolism during lactation was higher for sows in the Lo- $R$ and Lo-NR groups vs the Hi-R group as evidenced by the difference $(\mathrm{P}<.01)$ in serum urea- $\mathrm{N}$ concentration (table 3 ). However, serum urea- $\mathrm{N}$ 
TABLE 3. RELATIONSHIP OF LACTATION ENERGY INTAKE AND OCCURRENCE OF POSTWEANING ESTRUS TO SERUM AND URINE CONSTITUENTS ${ }^{a}$

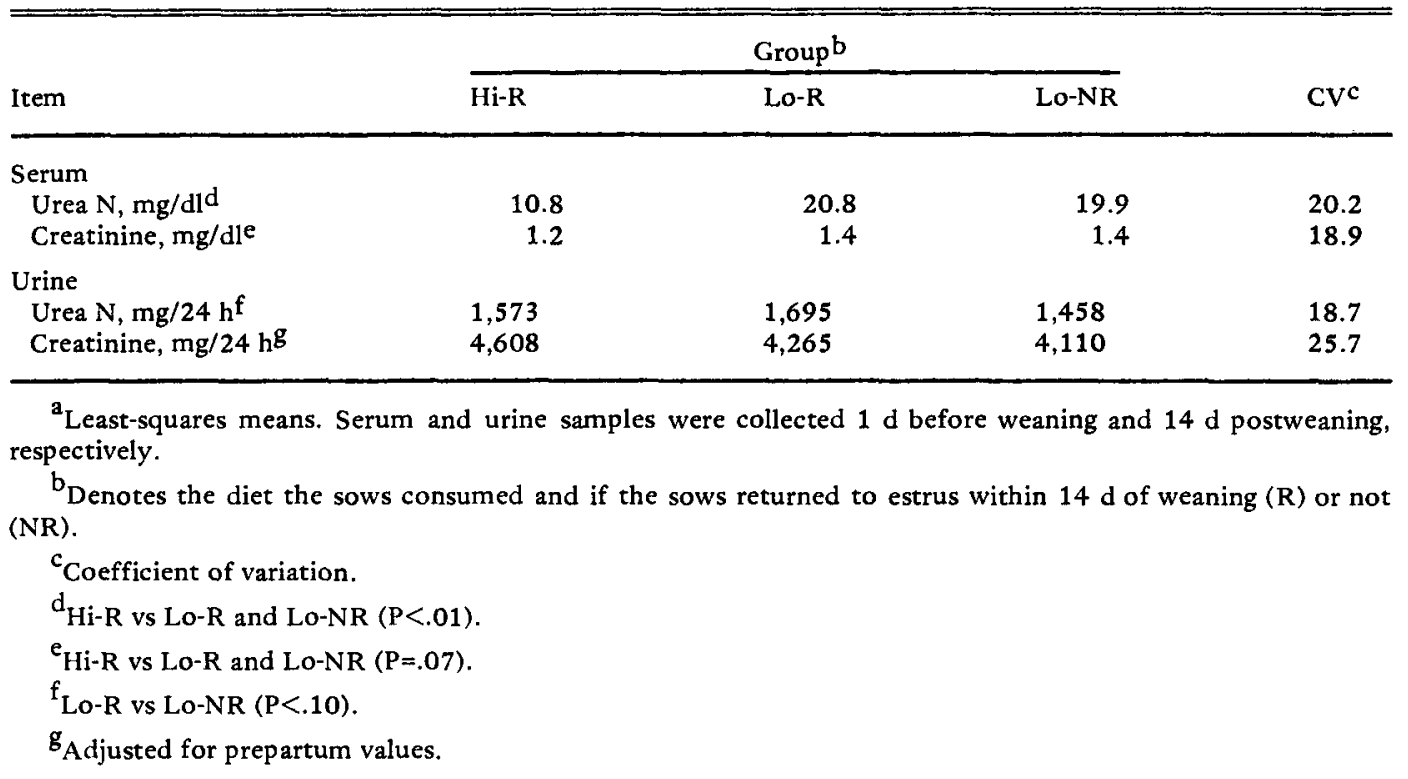

concentration of sows in the Lo-R group was not different (P>.10) from that observed for those in the Lo-NR group. These data indicate that an increased rate of amino acid catabolism probably occurred in energy-restricted sows. Reese et al. (1982a) reported a similar effect in energy-restricted sows. Also, elevated serum urea- $\mathrm{N}$ concentration was associated with slightly increased weight losses by sows fed restricted amounts of energy (Nelssen et al, 1982). However, because a higher rate of catabolism was not observed for sows in the Lo-NR vs the Lo-R group, the increased rate of amino acid catabolism due to energy restriction apparently was not associated with delayed estrus after weaning.

Serum creatinine concentration was higher $(\mathrm{P}=.07)$ for sows in the Lo-R and Lo-NR groups than for sows in the Hi-R group. No difference was observed between sows in the Lo-R and Lo-NR groups. Previously, Reese (1983) reported a significant increase (of the same magnitude as reported herein) in serum creatinine concentration in sows fed the Lo vs Hi diet during lactation. Serum creatinine increases with progressive wasting of muscles (Wallach, 1978). Apparently some muscle wasting occurred in energy-restricted sows, although it was independent of the time at which estrus occurred after weaning (Lo-R vs
Lo-NR, $P>.10$ ). Muscle catabolism apparently occurred in order to facilitate carbohydrate synthesis in energy-restricted sows and as a result contributed to the increased serum urea-N concentration.

From weaning to d 14 after weaning, alterations in urea-N synthesis occurred. Urea-N excretion rate was similar $(P>.10)$ for sows in the Lo-R and Lo-NR vs Hi-R groups; however, a lower $(\mathrm{P}<.10)$ excretion rate was observed for sows in the Lo-NR vs the Lo-R group. The increased urea- $N$ synthesis (demonstrated by increased serum urea- $N$ concentration) noted earlier in sows from the Lo-R and Lo-NR vs Hi-R group was therefore transient. Reasons for the association of reduced urea- $N$ synthesis with anestrus after weaning (Lo-NR group) are not apparent.

Creatinine excretion rates determined on $\mathrm{d}$ 15 and 16 postweaning were not different (P>.10) among groups of sows. However, a slight numerical reduction in creatinine excretion was observed in sows fed the Lo diet, indicating that some loss of muscle mass probably occurred during lactation. Creatinine excretion rates have been positively correlated with lean body mass in sheep (Van Niekerk et al., 1963) and humans (Forbes and Bruining, 1976) and with total body protein in sheep (Van Niekerk et al., 1963). Determination of 
lean body mass was delayed until $\mathrm{d} 14$ postweaning; at which time the sows would be expected to be gaining weight. This was necessary because according to Waterlow et al. (1972), calculating muscle mass from creatinine output is not reliable when body weight is rapidly decreasing.

Previously, muscle tissue losses were reported to occur in sows fed $12.2 \mathrm{Mcal}$ of digestible energy daily compared with higher amounts during lactation, but the weaning to estrus interval was not affected ( $O$ 'Grady et al., 1975). Also, Duee and Desmoulin (1982) noted that weight loss in lactating sows was associated with mobilization of muscle tissue; however, the relationship with estrous activity after weaning was not reported. Bryant and Smith (1982) concluded that skeletal muscles of lactating ewes may undergo a controlled depletion.

Because research reported herein suggests that loss of muscle tissue in sows fed $8 \mathrm{Mcal}$ of $\mathrm{ME}$ daily was not involved in delayed expression of estrus after weaning, catabolism of body fat rather than muscle tissue may have been the factor associated with delayed postweaning estrus. Estimates reveal that when animals rely on body tissues to supply their energy requirements, at least $80 \%$ of the energy is derived from fat and the remainder from protein
(Lindsay, 1975). These estimates support the relative use of body tissues for energy-restricted sows herein.

Adipose Tissue Composition. Total lipid content of adipose tissue obtained at weaning was less $(P=.05)$ for sows in the Lo- $R$ and Lo-NR group vs the Hi-R group (table 4). As previously discussed, measurable quantities of backfat were mobilized from sows in all groups, but the sows in the Lo-R and Lo-NR groups lost more backfat than those in the $\mathrm{Hi}-\mathrm{R}$ group. Thus, not only was less backfat remaining on energy-deprived sows at weaning, the lipid content of the existing backfat was also reduced. A similar situation was observed for steers fed a submaintenance diet (Trowbridge, 1911) and for infants with protein-calorie malnutrition (Cheek et al., 1970).

Fatty acid analysis of the lipid fraction revealed that as a percentage of methyl esters determined, the quantity of 18:0 and 18:1 was higher and lower $(P=.01)$, respectively, for sows in the Lo-R and Lo-NR groups vs Hi-R group. The percentages of the remaining fatty acids were similar $(P>.10)$ for sows in the Lo- $R$ and Lo-NR groups vs the Hi-R group. Seerley and Poole (1974) noted similar changes in the fatty acid composition of 3-d-old fasted pigs compared with newborn pigs. Boyd et al. (1982) infused neonatal pigs with labeled fatty

TABLE 4. RELATIONSHIP OF LACTATION ENERGY INTAKE AND OCCURRENCE OF POSTWEANING ESTRUS TO THE COMPOSITION OF SOW SUBCUTANEOUS ADIPOSE TISSUEa

\begin{tabular}{|c|c|c|c|c|}
\hline \multirow[b]{2}{*}{ Item } & \multicolumn{3}{|c|}{ Groupb } & \multirow[b]{2}{*}{$\mathrm{CV}^{\mathrm{c}}$} \\
\hline & $\mathrm{Hi}-\mathrm{R}$ & Lo-R & Lo-NR & \\
\hline Total lipid, $\mathrm{g} / 100 \mathrm{~g}$ wet tissued & 86.6 & 84.4 & 84.6 & 3.2 \\
\hline $\begin{array}{c}\text { Fatty acide } \\
14: 0 \\
16: 0 \\
16: 1 \\
18: 0^{f} \\
18: 1^{f} \\
18: 2\end{array}$ & $\begin{array}{r}1.3 \\
21.6 \\
2.9 \\
10.1 \\
46.7 \\
17.4\end{array}$ & $\begin{array}{r}1.3 \\
21.9 \\
2.9 \\
11.1 \\
45.3 \\
17.5\end{array}$ & $\begin{array}{r}1.3 \\
21.9 \\
2.8 \\
10.9 \\
45.5 \\
17.6\end{array}$ & $\begin{array}{l}8.3 \\
3.7 \\
9.6 \\
8.0 \\
2.7 \\
9.1\end{array}$ \\
\hline
\end{tabular}

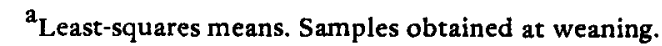

${ }^{b}$ Denotes the diet the sows consumed and if the sows returned to estrus within $14 \mathrm{~d}$ of weaning ( $R$ ) or not (NR).

${ }^{\mathrm{C}}$ Coefficient of variation.

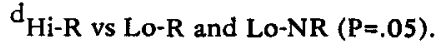

e Composition expressed as percentage of methyl esters.

$f_{\text {Hi-R vs Lo-R and Lo-NR (P=.01). }}$ 
acids and determined that $18: 1$ was oxidized to $\mathrm{CO}_{2}$ more rapidly than $16: 0,18: 0$ or $18: 2$.

Quantities of 14:0,16:0,16:1, 18:0,18:1 and 18:2 acids were determined in this study because they comprise approximately $95 \%$ of all fatty acids in swine adipose tissue (Lodge et al. 1978). Therefore, the data reported herein indicate that, of the fatty acids in swine adipose tissue, 18:1 contributed more than its share to the reduction in lipid content of that tissue from energy-restricted sows.

No differences in lipid and fatty acid content of adipose tissue were observed between the Lo-R and Lo-NR groups of sows. Therefore, the lack of estrous activity by $d 14$ postweaning cannot be explained by changes in the adipose tissue components evaluated in this study.

\section{Literature Cited}

Adam, J. L and I. J. Shearer. 1975. Effects on sow and litter performance of energy intake in lactation and feeding patterns following weaning. New Zealand J. Exp. Agr. 3:55.

Anthony, R. V., R. J. Kittok, E. F. Ellington and M. K. Nielsen. 1981. Effect of zeranol on growth and ease of calf delivery in beef heifers. J. Anim. Sci. 53:1325.

Boyd, R. D., R. A. Britton, H. Knoche, B. D. Moser, E. R. Peo, Jr. and R. K. Johnson. 1982. Oxidation rates of major fatty acids in fasting neonatal pigs. J. Anim. Sci. 55:95.

Brooks, P. H., D.J.A. Cole, P. Rowlinson, V. J. Croxson and J. R. Luscomb. 1975. Studies in sow reproduction. 3. The effect of nutrition between weaning and remating on the reproductive performance of multiparous sows. Anim. Prod. 20:407.

Bryant, D.T.W. and R. W. Smith. 1982. The effect of lactation on protein synthesis in ovine skeletal muscle. J. Agr. Sci. (Camb.) 99:319.

Cheek, D. B., D. E. Hill, A. Cordano and G. G. Graham. 1970. Malnutrition in Infancy: Changes in muscle and adipose tissue before and after rehabilitation. Pediat. Res. 4:135.

Cox, N. M., J. H. Britt, W. D. Armstrong and H. D. Alhusen. 1983. Effect of feeding fat and altered weaning schedule on rebreeding in primiparous sows. J. Anim. Sci. 56:21.

Cox, N. M., K. L. Esbenshade and J. H. Britt. 1982. Relationships among heart girth, backfat and rebreeding performance in sows whose litters were weaned as one or two groups. J. Anim. Sci. 55(Suppl. 1): 181.

Duee, P. H. and B. Desmoulin. 1982. Changes in the body composition of nulliparous sows during the reproductive cycle: Effect of the dietary protein level during gestation. 14th French Swine Res. Days Rep. Institut Technique du Porc. Paris, France.

Elsley, F.W.H., R. M. MacPherson and I. McDonald. 1968. The influence of intake of dietary energy in pregnancy and lactation upon sow productivity. J. Agr. Sci. (Camb. ) 71:215.
Fahmy, M. H., W. B. Holtmann and R. D. Baker. 1979. Failure to recycle after weaning, and weaning to oestrus interval in crossbred sows. Anim. Prod. 29:193.

Folch, J., M. Lees and G. H. Sloane-Stanley. 1957. A simple method for the isolation and purification of total lipids from animal tissue. J. Biol. Chem. 226: 497

Forbes, G. B. and G. J. Bruining. 1976. Urinary creatinine excretion and lean body mass. Amer. J. Clin. Nutr. 29:1359.

Frankel, S., S. Reitman and A. C. Sonnenwirth. 1970. Gradwohl's Clinical Laboratory Methods and Diagnosis, Vol. 1 (7th Ed.). p 340, 343. C. V. Mosby Co., St. Louis, MO.

Grizzle, J. E., C. F. Starmer and G. G. Koch. 1969 Analysis of categorical data by linear models. Biometrics 25:489.

Hovell, F.D.D., J. G. Gordon and R. M. MacPherson. 1977. Thin sows. 2. Observations on the energy and nitrogen exchanges of thin and normal sows in environmental temperatures of 20 and $5 \mathrm{C}$. J. Agr. Sci. (Camb.) 89:523.

Lindsay, D. B. 1975. Fatty acids as energy sources. Proc. Nutr. Soc. 34:241.

Lodge, G. A., N. K. Sarker and J.K.G. Kramer. 1978. Fat deposition and fatty acid composition in the neonatal pig. J. Anim. Sci. 47:497.

MacPherson, R. M., F.W.H. Elsley and R. I. Smart. 1969. The influence of dietary protein intake during lactation on the reproductive performance of sows. Anim. Prod. 11:443.

Nelssen, J. L., A. J. Lewis, B. D. Moser, E. R. Peo, Jr. and J. D. Crenshaw. 1982. Effects of restriction and source of energy intake during lactation on sow and litter performance. J. Anim. Sci. 55(Suppl. 1):288

NRC. 1979. Nutrient Requirements of Domestic Animals, No. 2. Nutrient Requirements of Swine. Eighth Revised Ed. National Academy of Sciences-National Research Council, Washington, DC.

O'Grady, J. F. 1971. Level and source of protein in the diets of lactating sows. Irish J. Agr. Res. 10: 17 .

O'Grady, J. F., F.W.H. Elsley, R. M. MacPherson and I. McDonald. 1973. The response of lactating sows and their litters to different dietary energy allowances. 1. Milk yield and composition, reproductive performance of sows and growth rate of litters. Anim. Prod, 17:65.

O'Grady, J. F., F.W.H. Elsley, R. M. MacPherson and I. McDonald. 1975. The response of lactating sows and their litters to different dietary energy allowances. 2. Weight changes and carcass composition of sows. Anim. Prod. 20:257.

Patrick, J., P. J. Reeds, A. A. Jackson, A. Seakins and D.I.M. Picou. 1978. Total body water in malnutrition: The possible role of energy intake. Brit. J. Nutr. 29:417.

Petherick, D. J., P. Rowlinson and M. J. Bryant. 1977. Variation in the occurrence of oestrus in lactating sows in response to grouping, boar presence and an elevated feed level. Anim. Prod. 24:155.

Reese, D. E. 1983. Influence of energy intake during lactation on the interval from weaning to first estrus in sows. Ph.D. Dissertation. Univ. of Nebraska, Lincoln. 
Reese, D. E., B. D. Moser, E. R. Peo, Jr., A. J. Lewis, D. R. Zimmerman, J. E. Kinder and W. W. Stroup. 1982a. Influence of energy intake during lactation on the interval from weaning to first estrus in sows. J. Anim. Sci. 5 5:590.

Reese, D. E., B. D. Moser, E. R. Peo, Jr., A. J. Lewis, D. R. Zimmerman, J. E. Kinder and W. W. Stroup. 1982b. Influence of energy intake during lactation on subsequent gestation, lactation and postweaning performance of sows. J. Anim. Sci. 55:867.

SAS. 1979. SAS User's Guide. Statistical Analysis System Institute, Inc., Cary, NC.

Schied, R. J., E. H. Dolnick and C. E. Terrill. 1970. A quick method for taking biopsy samples of the skin. J. Anim. Sci. 30:771.

Seerley, R. W. and D. R. Poole. 1974. Effect of prolonged fasting on carcass composition and blood fatty acids and glucose of neonatal swine. J. Nutr. 104:210.

Steel, R.G.D. and J. H. Torrie. 1980. Principles and Procedures of Statistics (2nd Ed.). McGraw-Hill
Book Co., New York.

Trowbridge, P. F. 1911. The resorption of fat. Proc. Amer. Soc. Anim. Prod. p 13.

Van Niekerk, B.D.H., J. T. Reid, A. Bensadoun and O. L. Paladines. 1963. Urinary creatinine as an index of body composition. J. Nutr. 79:463.

Varley, M. A. and D.J.A. Cole. 1976. Studies in sow reproduction. 1. The effect of level of feeding in lactation and during the interval from weaning to remating on the subsequent reproductive performance of the early weaned sow. Anim. Prod. $22: 71$.

Varley, M. A. and D.J.A. Cole. 1978. The relationship between the weight change of the sow and her reproductive output. Anim. Prod. 26:368 (Abstr.).

Wallach, J. 1978. Interpretation of Diagnostic Tests (3rd Ed.). Little, Brown and Co., Boston, MA.

Waterlow, J. C., R. J. Neale, L. Rowe and I. Palin. 1972. Effects of diet and infection on creatine turnover in the rat. Amer. J. Clin. Nutr. 25:371.

Whittemore, C. T., M. F. Franklin and B. S. Pearce. 1980. Fat changes in sows. Anim. Prod. $31: 183$. 